\title{
Pros

\author{
HACIA UNA TEORÍA LITERARIA POST-SECULAR: \\ REPENSAR LA CRÍTICA LIBERAL DE LA RELIGIÓN \\ A TRAVÉS DE FLORA TRISTÁN, PAUL GAUGUIN Y VARGAS \\ LLOSA EN EL PARAÍSO EN LA OTRA ESQUINA \\ POST-SECULAR THEORY: RETHINKING RELIGION THROUGH \\ FLORA TRISTÁN, PAUL GAUGUIN AND VARGAS LLOSA IN \\ EL PARAÍSO EN EL OTRO ESQUINA \\ Alfredo Ignacio Poggi \\ University of North Georgia \\ alfredo.poggi@ung.edu
}

RESUMEN: Este artículo postula que la crítica a la religión es la temática central de la novela El paraíso en la otra esquina, brindando una alternativa al desafío crítico de encontrar un factor unificador de las dos historias de la obra, tanto de Flora Tristán como de Paul Gauguin. Utilizando el concepto post-secular de Jürgen Habermas, las tres hipótesis de la secularización de José Casanova, la crítica a una visión esencialista de la religión de Talal Asad y los tres estadios del desarrollo secular de Charles Taylor, este análisis tiene el objetivo de cuestionar la oposición binaria entre lo secular y lo religioso que permea la obra de Vargas Llosa. A través de una revisión de la narrativa de la secularización, eurocentrista y moderna, presente en la novela, se intenta puntualizar la vaguedad de la definición de lo religioso, la porosidad del cuadro inmanente creado por el autor, y la resistencia del lector a una oposición binaria transhistórica que sugiere potencialidades humanas naturales, las cuales se realizan al liberarse de la religión.

PALABRAS ClAVE: Vargas Llosa, Teoría post-secular, secularización, religión, Paul Gauguin, Flora Tristán

ABSTRACT: This article postulates that the criticism of religion is the central theme of the novel Paradise in the other corner, providing an alternative to the critical challenge of finding a unifying factor of the two stories of the work, both Flora Tristan and Paul Gauguin. Using the post-secular concept of Jürgen Habermas, the three hypotheses of the secularization of José Casanova, the critique of an essentialist vision of the religion of Talal Asad and the three stages of the secular development of Charles Taylor, this analysis has the objective of questioning 
the binary opposition between the secular and the religious that permeates the work of Vargas Llosa. Through a revision of the narrative of secularization, Eurocentrist and modern, present in the novel, we try to point out the vagueness of the definition of the religious, the porosity of the immanent picture created by the author, and the resistance of the reader to a transhistorical binary opposition that suggests natural human potentialities, which are realized when liberating from religion.

Keywords: Vargas Llosa, Post-secular Theory, Secularization, Religion, Paul Gauguin, Flora Tristán

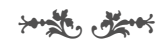

Publicada en 2003, la novela El paraíso en la otra esquina narra los sucesos en las vidas de dos personajes históricos, Flora Tristán y Paul Gauguin, impregnadas de rupturas emocionales, problemas económicos y conflictos sociales. En los capítulos impares, Vargas Llosa se focaliza en la escritora, feminista y defensora de los obreros, Flora Tristán, la cual se muestra viajando al final de su vida por las distintas ciudades y pueblos de su país, Francia, promocionando su ansiada Unión Obrera. En esta búsqueda de una utopía social, propia de la Europa de principios del siglo xIX, Vargas Llosa alterna el pasado y el presente de Flora Tristán, para incluir los sucesos biográficos de la escritora, como por ejemplo, la pérdida de la herencia de su padre, el rechazo de su familia peruana, sus problemas económicos, su viaje accidentado al Perú, su matrimonio fallido, el intento de asesinato por parte de su esposo, el rechazo de la sociedad francesa de la época, el abandono de sus hijos, entre otros.

En los capítulos pares, por otro lado, Vargas Llosa narra las aventuras del pintor francés, Paul Gauguin, teniendo como punto de referencia sus cuadros. Cada capítulo par gira en torno a la creación de uno de sus pinturas y al igual que con Flora Tristán, el presente narrativo de Gauguin se alterna con su pasado, plagado de excesos y de una búsqueda de lo primitivo en el arte que lo lleva a viajar alrededor del mundo. Además de tener una vida conflictiva y repleta de viajes, similar a Flora Tristán, Paul Gauguin fue también el nieto de esta escritora francesa, aunque nunca la conoció, y quizás sea este parentesco una de las mayores razones que encontró Vargas Llosa para juntar a ambos personajes históricos en la misma novela.

En sus novelas como La fiesta del chivo, Vargas Llosa alterna las historias de los distintos personajes a través de los diferentes capítulos, los cuales no tienen conexiones directas hasta llegar al clímax de la narración. No obstante, el desafío crítico que tiene El paraíso en la otra esquina reside en hallar el punto de conexión que une a ambas historias, que a primera vista parecen ser composiciones independientes. Algunos críticos como Paco Marín sostienen que es imposible dicha tarea y afirman que se trata de dos novelas separadas. De hecho, el único comentario de la novela en la cubierta posterior de la edición Santillana, 
hecha por el periódico El País, dice: "no es una novela grande sino dos grandes novelas, dos narraciones históricas...Libro magistral, que son dos, como dos son los paraísos evocados".

Otros críticos como Martha Sánchez, Rita Gnutzmann y Edwald Weitzörfer no cuestionan la distancia entre las dos historias de la novela y consideran que la relación familiar de los dos personajes, como las búsquedas de sus ideales y los enfrentamientos con sus contemporáneos, son razones suficientes para incluir a Tristán y Gauguin en la misma narración. En este sentido, estos críticos parecen coincidir con Vargas Llosa, quien afirma que se trata de dos personajes en búsqueda de utopías terrenales imposibles, y por ende ingenuos, pero que en dichos caminos hacia lo irrealizable, dejaron beneficios a la humanidad, configurando dos vidas, en cierto sentido, heroicas para su tiempo (2003b).

Finalmente, críticos como Ricardo Gutiérrez-Mouat intentan unir las dos historias bajo categorías comunes más elaboradas, sin simplificar ni obviar la distancia entre ambos personajes. Por ejemplo, Gutiérrez-Mouat desarrolla un análisis a través del concepto de cosmopolitismo, según el cual Flora Tristán estaría buscando un cosmopolitismo de la igualdad, en el que las mujeres y los obreros sean aceptados, mientras que Paul Gauguin lucharía por un cosmopolitismo de la diferencia, para liberarse de la sociedad occidental burguesa (2008: 397-398). También Nataly Villena Vega utiliza la misma idea de cosmopolitismo como herramienta central para la crítica de la obra.

En mi análisis elaboraré una lectura diferente de la novela, probando que la temática unificadora de la misma es la crítica a la religión, siguiendo el liberalismo del autor peruano. Mi idea está sustentada en el hecho de que, si bien las historias de Flora Tristán y Paul Gauguin representan dos tramas narrativas diferentes en búsqueda de estilos de vidas aparentemente opuestos, en todos sus capítulos, los mayores personajes antagónicos de ambos tienen la misma característica: están siempre asociados a lo religioso, especialmente, a la Iglesia Católica. Además, las mayores disputas que impregnan de incertidumbre y dinamismo a ambas historias, se dan entre los dos personajes principales y los religiosos, ya sean sacerdotes, obispos, monjas, pastores protestantes o personas extremadamente devotas. De hecho, ambas historias, y por ende la novela, como se expondrá más adelante, terminan con las alocuciones de dos personajes religiosos frente a los cadáveres de Tristán y Gauguin respectivamente.

Aunque los críticos de la novela no hayan mencionado este aspecto anteriormente, y ni siquiera el mismo autor, se puede identificar suficiente evidencia literaria para probar la postura de mi análisis. Utilizando dos contextos históricos distintos, el escritor peruano critica a la religión desde dos perspectivas diferentes, y algunas veces opuestas. Sin embargo, ambas perspectivas se conectan con la postura liberal del autor. Según José Miguel Oviedo, en El paraíso en la otra esquina, Vargas Llosa utiliza la novela con un espíritu ensayístico para pensar y expresar sus preocupaciones morales e ideológicas (2007: 73). Por otro lado, Oswaldo Estrada sostiene que, en El paraíso en la otra esquina, Vargas Llosa recuenta unas trayectorias de reivindicaciones y utopías sociales y personales, lejos del fervor religioso y nacionalista (2017: 126). 
Aun cuando este trabajo busca limitarse enteramente al análisis textual de la novela, por que es consciente de los cambios de ideas que experimentan los autores a lo largo de sus vidas; también reconoce la relevancia de tener presente el antecedente ideológico del escritor. A lo largo de su vida, Vargas Llosa ha manifestado implícita y explícitamente su apoyo al liberalismo político en sus novelas y ensayos. La llamada de la tribu, ${ }^{1}$ publicado en el 2018, es la obra del autor peruano que mejor sistematiza su visión ideológica y su conversión desde el marxismo y el existencialismo al liberalismo. En su libro, Vargas Llosa realiza una defensa de por qué cree que el liberalismo es la corriente de pensamiento político que mejor garantiza las libertades individuales y el progreso social (2018). Además, dentro de su visión liberal clásica, la religión se presenta como un obstáculo que limita las libertades humanas si se involucra en la función social. Es decir, la religión debe secularizarse (reducir su poder, privatizarse y separarse del Estado) para vivir armoniosamente en las sociedades liberales contemporáneas.

Para analizar la narrativa de la novela de Vargas Llosa, se emplearán los conceptos de los tres estadios dentro del proceso de secularización propuestos por Charles Taylor en su libro A Secular Age: el ancien régime, la edad de la movilización y la edad de la autenticidad. El filósofo canadiense Charles Taylor es considerado uno de los pensadores más influyentes de las últimas décadas, y está asociado al comunitarismo junto a otros autores como Alasdair Maclntyre, Michael Sandel, y Michael Walzer. En una reacción al libro Teoría de la Justicia de filósofo liberal John Rawls, el comunitarismo critica la absolutización del individuo y su libertad frente al valor fundamental de la comunidad en la existencia humana. Además, el comunitarismo reconoce la importancia de la dimensión religiosa en la organización y las reivindicaciones sociales contemporáneas. En su libro A Secular Age, Charles Taylor analiza las narrativas de la secularización en Occidente con el fin de responder la primera oración de su obra: ¿Qué significa vivir en una edad secular?, y pone en descubierto los "supuestos" ideológicos liberales sobre lo religioso (2007: 1).

Finalmente, este artículo busca mostrar también la dificultad de mantener una oposición binaria entre lo secular y lo religioso dentro de una narrativa. Siguiendo la postura del antropólogo Talal Asad y yendo más allá del aspecto crítico del autor, se puede evidenciar en la novela cómo lo religioso no tiene una

\footnotetext{
${ }^{1}$ En el libro La Llamada de la tribu, Vargas Llosa narra su camino ideológico desde su participación en un grupo marxista universitario en la Universidad de San Marcos, su desilusión con la Revolución cubana, su refugio en el existencialismo de Sartre, y finalmente su conversión al liberalismo gracias a sus lecturas y a su experiencia personal en la Inglaterra de Margaret Thatcher, aliada a su vez de Ronald Reagan. Aun cuando el autor peruano está en desacuerdo con el conservadurismo de estos dos últimos líderes, les reconoce su importancia en el impulso de las libertades individuales. Luego, el libro prosigue con siete capítulos, cada uno dedicado a un pensador liberal que lo marcó a lo largo de su vida: Adam Smith, José Ortega y Gasset, August von Hayek, Karl Popper, Raymond Aron, Isaiah Berlin y Jean-Francois Revel. En las palabras del mismo autor, el objetivo del libro es defender al liberalismo frente a los ataques de las izquierdas y los conservadores. Para Vargas Llosa, el liberalismo no es dogmático, no es anarquista ni se limita a promover solo la libertad de mercado (2018). Sino que promueve las libertades individuales hasta sus máximas consecuencias contra los intentos totalitarios y centralistas, fomenta un Estado pequeño frente a las burocracias estatistas y defiende una humildad política que le permite reconocer sus errores y cambiar para mejorar (2018).
} 
definición universal, sino que es un producto histórico de los procesos discursivos (2012: 29). En la historia sobre Flora Tristán la definición de lo religioso no es la misma que en la narración sobre Paul Gauguin y, de hecho, por momentos, tienen significados opuestos.

\section{HACIA UNA LECTURA POST-SECULAR}

Etimológicamente, la palabra secular procede del término latino medieval, saeculum, que permitía clasificar la vida humana en una dualidad: el mundo religioso (ciudad de Dios) y el mundo secular (ciudad del hombre), mientras que la Iglesia se encontraba en el medio de ambos (Casanova 2012: 19-20). En el derecho canónico, se utilizó por primera vez el término secularización para identificar el proceso por el cuál un monje volvía al mundo y dejaba el claustro (20). En este sentido, el monje se convertía en un sacerdote secular. Luego, durante los comienzos de la Modernidad, el término secularización fue identificándose con el proceso de expropiación de las posesiones de la Iglesia Católica, las cuales pasaban a manos de los reinos o estados nacionales, y significaba, a su vez, el paso de los usos religiosos o eclesiásticos a los usos civiles o laicos (20).

Por último, como apunta Casanova, los fundadores de las ciencias sociales como Max Weber y Émile Durkheim, entre otros, comenzaron a conectar el proceso de secularización con la modernización, pronosticando el declive y la privatización de la religión en las sociedades desarrolladas (21-22), algo que se fue convirtiendo en un paradigma incluso hasta finales del siglo xx, y el cuál no se sometía a ninguna comprobación empírica ni refutación filosófica. Lo secular se fue transformando así en sinónimo de libertad y desarrollo humano y, opuesto a lo religioso, signo de irracionalidad y barbarie.

Este debate sobre la secularización se ha incrementado en la última década, como sostiene Maczynska, y muchos pensadores han clasificado este sentir con el prefijo "post", en el término post-secular, el cuál es relativamente reciente y ha creado discordia en las academias (2009: 73). El volumen creciente de bibliografía sobre el tema en la última década y la participación en este debate de grandes pensadores de nuestro tiempo como Jürgen Habermas y Charles Taylor, demuestran un replanteamiento en los análisis sobre lo secular y lo religioso, como también ha motivado a una relectura más crítica sobre sus definiciones en Occidente.

El replanteamiento de este tema comenzó principalmente desde la sociología, en obras paradigmáticas como la de José Casanova llamada Religion in the Public Sphere, las cuales cuestionaron la teoría de la secularización tradicional. Según Casanova, la secularización no es un concepto unificado, sino que encierra tres hipótesis diferentes: la decadencia de las prácticas y creencias religiosas, la privatización de la religión, y la distinción o emancipación de las esferas seculares de las instituciones religiosas (2012: 33). Frente a las teorías de secularización hechas por las mayorías de los fundadores de las ciencias sociales, que pronosticaban el declive de lo religioso, las sociedades globalizadas, exceptuando algunas europeas, han mantenido signos contundentes de religiosidad hasta 
la actualidad, e incluso se han dado incrementos notables en algunos casos (50). Además, como observó Casanova, lo religioso entró nuevamente al debate público en los años ochenta, cuestionando la tesis de la privatización de la religión en las sociedades modernas a favor de lo secular (31). Y quizás el atentado del 11 de septiembre en Nueva York, como ninguna otra cosa, simbolizó la entrada de lo religioso al escenario público y obligó a los pensadores a replantearse las teorías tradicionales de secularización.

Otro elemento importante para el replanteamiento de esta temática fue sin duda Estados Unidos. A diferencia de los países europeos en los que la modernización se dio paralelamente a la secularización, la experiencia en Estados Unidos fue diferente. En un principio, los teóricos europeos clasificaban a Estados Unidos como una excepción. No obstante, en las últimas décadas, los sociólogos han percibido como en otros países como India y Japón, entre muchos otros, el resurgimiento de lo religioso se dio conjuntamente con la modernización de sus sociedades. En este sentido, la conexión entre modernización y secularización se comenzó a cuestionar y a calificar como un eurocentrismo (Casanova 2012: 62-64).

Este escenario sociopolítico se traduce en los estudios culturales y literarios como una revisión crítica de las narrativas de secularización moderna, ya sea para mejorar el proyecto moderno como en Habermas, para cuestionarlo y desplazarlo como en Talal Asad, o para recrear una metanarrativa más sofisticada como en Charles Taylor (Huggan 2010: 754, Maczynska 2009: 74).

A pesar de que Charles Taylor no es defensor del concepto post-secular en términos sociológicos, las ideas en su libro A Secular Age también apuntan a la revisión de las narrativas de la secularización y brindan herramientas útiles para la crítica literaria. Según Taylor, el proceso de secularización en Occidente, o más específicamente en los países del Atlántico del Norte, produjo un declive de ciertas formas de religiosidad, pero al mismo tiempo generó otras nuevas (2007: 437). Además, para el filósofo canadiense, la secularización significó una masificación de posibilidades distintas al cristianismo, un humanismo no creyente que estaba presente entre las élites, pero que a partir de finales del siglo XVIII y los siguientes siglos comenzó un proceso de difusión y asimilación entre las clases más bajas y el público en general desde las teorías hacia el imaginario social (437).

Siguiendo el estilo weberiano de los tipos ideales, Taylor identifica tres estadios con características particulares dentro del proceso de secularización: el ancien régime, la edad de la movilización y la edad de la autenticidad. A estos estadios, según Taylor, les corresponden unos imaginarios sociales respectivos, es decir, una colección de entendimientos sobre cómo nos relacionamos en la sociedad. A diferencia de las teorías, el imaginario social no está articulado y permea los diferentes estratos sociales, que los dan por supuestos, sin cuestionarlos (2007: 171-173).

En mi análisis del libro de Vargas Llosa, sostengo que los dos personajes principales se encuentran en medio de estos estadios propuestos por Taylor e intentan promover en el imaginario social unas teorías o formas de vida de unas 
élites. En el caso de Flora Tristán, deseando el paso a una edad de la movilización, se enfrenta a los sacerdotes y religiosos devotos en Francia y Perú que representan el ancien régime. Por otro lado, Paul Gauguin encarna una lucha por una masificación de la edad de la autenticidad, pero se debe enfrentar a los religiosos, representantes de una edad de la movilización.

Además de la revisión de las narrativas de la secularización hechas por Taylor, las posturas postmodernas han brindado herramientas teóricas a los críticos post-seculares para cuestionar la oposición binaria entre lo secular y lo religioso (Hamner 2009: 94, Maczynska 2009: 74), y los trabajos postcoloniales han aportado una crítica a las categorías europeas, en las cuales se incluye la de una secularización lineal moderna (Huggan 2010: 755, Maczynska, 2009: 76).

Por eso, más allá de los debates sobre la definición exacta y apropiada del término, en este trabajo se entiende la crítica post-secular como una revisión de las narrativas europeas modernas de los procesos de secularización, cuestionando la oposición binaria entre lo secular y lo religioso, que se cuelan incluso hasta hoy en las narraciones culturales y literarias. Como se mostrará más adelante, Vargas Llosa crea una oposición entre los personajes principales y los religiosos, configurando a estos últimos como agentes que impiden el desarrollo humano y su libertad. Al igual que las substraction stories, identificadas por Charles Taylor en las mayorías de las teorías sociales tradicionales de la modernidad (2007: 2627), Vargas Llosa parece sugerir que el ser humano tuviera unas potencialidades naturales, que solo pueden realizarse si se liberan de la religión. Es decir, lo secular se define como una liberación de lo religioso, y por ello, es beneficioso.

No obstante, las oposiciones que dividen a Flora Tristán y Paul Gauguin de los religiosos se intercambian en las dos historias, y en la mayoría de los casos son contrarias. Es decir, a pesar del intento del autor de mostrar a la religión como un concepto estable que impide el desarrollo humano, al contrastar las dos historias, se aprecia la artificialidad histórica y narrativa de lo que se considera religioso. Lo que representan los religiosos en la historia de Flora, y por lo cual se los critica, es lo contrario en el caso de Paul Gauguin. Uno de los ejemplos más evidente es la posición que tienen ambos personajes con respecto a los ritos y los símbolos, que aspiran a lo superstición y son aupado por los representantes católicos. Como se mostrará más adelante, Flora condena estas prácticas y a los religiosos por defenderlas, mientras que, por el contrario, Paul las favorece y los misioneros las atacan. En este sentido, la oposición binaria desde la cual se sostiene la crítica a la religión en la novela se tambalea.

\section{FLora TRISTÁN y LA EdAd DE LA MOVILIZACIÓN}

En su tour a través de Francia, que sirve como línea central en la historia de Flora Tristán, esta intenta convencer a los obreros sobre los beneficios de la Unión Obrera. Siguiendo los socialistas utópicos de su época, Flora propone un proyecto utópico alternativo a los muchos otros que se estaban dando en su momento. A pesar de las diferencias que tenía Flora frente a los otros utopistas, 
nunca se percibe en su historia un enfrentamiento irreconciliable ni agresivo con ellos.

Pero, como se mencionó anteriormente, sí se pueden identificar pugnas constantes de Flora con religiosos en todos los capítulos. Y estos enfrentamientos producen, a su vez, los debates más extensos de su historia, como también los mayores picos conflictivos en la trama. En el capítulo I, por ejemplo, Flora Tristán tiene una primera discusión con los obreros, a quienes les intenta hacer comprender que ser cristiano es estar a favor del divorcio, dentro de una reinterpretación bíblica a estar del lado de los más vulnerables, en este caso, de las mujeres (2003a: 18). En el debate teológico sobre si Jesús prohibió el divorcio por un mandato conservador o para proteger a las mujeres frente al abuso patriarcal y brindarles sustento económico, Flora se inclina obviamente por este último argumento. Sin embargo, su primer enfrentamiento agresivo en la novela es con un religioso, cuando habla con el Padre Fortín:

Flora le explicó que no: creía en Jesús pero no en la Iglesia, porque, en su criterio, la religión católica coactaba la libertad humana debido a su sistema vertical. Y sus creencias dogmáticas sofocaban la vida intelectual, el libre albedrío, las iniciativas científicas. Además, sus enseñanzas... atizaban los prejuicios que habían hecho de la mujer poco menos que una esclava [...] era improbable que algún obispo patrocinara una acción social de signo abiertamente anticatólico. (Vargas Llosa 2003a: 22-23)

Y finalizando el primer capítulo, Flora concluye: "-Usted es uno de esos curas que volvería a llenar las plazas de hogueras para quemar a todos los seres libres e inteligentes del mundo, padre-le dijo a modo de adiós" (24).

En el capítulo III, el siguiente sobre Tristán, además de criticar las vírgenes y santos pintarrajeados de las iglesias de Avallon (2003: 50) y Dijón (2003: 63), que los califica como si parecieran sapos, al igual que las de Perú, Flora tiene un nuevo enfrentamiento, esta vez con el obispo de Dijón que se dignó a atenderla después de que insistiera tres veces: "Se había leído el librito y, antes de que Flora abriera la boca, la colmó de elogios [...] Pero, pero, siempre había un pero... En el caso de Flora, no ser católica. ¿Acaso se podía hacer una obra grande, moral, útil para el espíritu, al margen del catolicismo? [...] Si se formaba la Unión Obrera...él la combatiría" (Vargas Llosa 2003a: 66).

En el capítulo $V$, se refuerza nuevamente la oposición entre desarrollo y modernidad versus atraso y religión:

Lyon...ciudad clerical, que apestaba a incienso y sacristía [...] las asnerías oscurantistas que derramaban sobre ellas unos curas predicadores de la resignación y la servidumbre al poderoso. Lo más triste era comprobar que los pobres eran la inmensa mayoría de fieles. [...] ¡La Edad Media, en el corazón de una de las ciudades más industrializadas y modernas del mundo! [...] Divisó, por las rejas, a las hermanas de la Caridad, que tenían...escuelas para pobres. ¡Cuando no! Hábitos y guardias brazo a brazo, para tener atrapados a los pobres... (Vargas Llosa 2003a: 113) 
En este capítulo también, Flora consigue hablar con unos "cura rebeldes", a quienes sugiere rebelarse contra su institución religiosa: "Su palabra llegó incluso al corazón del enemigo, la Iglesia" (115).

En el capítulo impar siguiente, el VII, Vargas Llosa opone de nuevo a Flora y la Iglesia Católica: "En los cuatro talleres de tejedores...se quedó sorprendida al saber que, al principio y el final de la jornada, obreras y obreros rezaban... Cuando les explicó que no era católica, porque, a su juicio, la Iglesia era una institución opresora de la libertad humana, la miraron con tanto espanto que temió que la insultaran... salió convencida que perdía el tiempo" (149).

En este capítulo, también aparecen los importantes personajes del Eunuco Divino e Ismaelillo, de cuando Flora residía en la casa de Mariano de Goyeneche, antes de partir a Perú. Para Flora, ambos eran los seres más católicos que había conocido, y sus conductas le causaba risa, eran como unas caricaturas (152). Ismaelillo, según Flora, además escondía en su piedad católica un deseo sexual por ella, lo cual lo dejaba siempre en ridículo (153-155).

Los enfrentamientos con las instituciones religiosas y sus devotos continúan, por ejemplo, en el capítulo IX, cuando las mujeres de la iglesia expulsan a Flora del templo llamándola "judía" por estar comiendo dentro del mismo (204), y en el capítulo XI se narra cómo las monjas sacan provecho de todo para conseguir dinero, hasta vendiendo hábitos a los moribundos en un Perú supersticioso y medieval (252).

En el siguiente capítulo impar, el XIII, se describe a los conventos y monasterios peruanos con sus excesivos lujos, en los cuales las monjas podían alojarse con cuatro esclavas y cuatro sirvientas (280-281). Y en el capítulo XV, Vargas Llosa explicita de nuevo la oposición entre Flora y los sacerdotes:

Desde los púlpitos, los curas de la ciudad amotinaban contra ella a esa masa fanatizada que atestaba las iglesias, la que salían a buscarla por las calles de Nimes para lincharla...con las caras desfiguradas de odio...oliendo a incienso [...]. Que los púlpitos hubieran convencido a los obreros de que era bueno ser explotados porque así entrarían al Paraíso, la desmoralizó.... (Vargas Llosa 2003a: 331- 322)

\section{Y Vargas Llosa prosigue:}

Flora, respondiéndose, intentó ilustrarlo, explicándole que todos los sacerdotes -judíos, protestantes y mahometanos, pero principalmente los católicoseran aliados de los explotadores y ricos porque con sus sermones mantenían resignada la humanidad doliente con la promesa del Paraíso, cuando lo importante no era ese improbable premio celestial... la sociedad libre y justa ... se debía construir aquí y ahora. (Vargas Llosa 2003a: 330)

En los últimos capítulos impares de la novela de Vargas Llosa, del XVII al XXI, aun cuando algunos religiosos como los jesuitas en Francia (396) y los anglicanos en Inglaterra (445), con sus centros de atención a los pobres, y el líder irlandés católico Danie O'Connell (439) reciben tímidos elogios y se libran de los ataques, 
el tono anti-religioso continua. Por ejemplo, en el capítulo XIX, se lee: "A uno de ellos que...insistía en que se vistiera para mostrarle las iglesias y murallas medievales...le respondió: -¡Qué me importa a mí las piedras viejas, cuando hay tantos seres humanos con problemas por resolver! ¡Sepa usted que yo cambiaría, sin vacilar, la más bella iglesia de la Cristiandad por un solo obrero inteligente!" (431).

El final de la historia de Flora pone claramente de manifiesto la oposición del personaje a lo clerical y a lo religioso. En el último episodio, un "falso" sacerdote la visita en su lecho de muerte, cuando ella supuestamente no podía ya razonar, y afirma al mundo que Flora se había arrepentido de su postura antiiglesia y se había convertido al catolicismo. Luego se revela que ese "falso" sacerdote era el Eunuco Divino, la persona más católica que había conocido Flora, y por ende, para ella, una caricatura de ser humano. Así, en su velorio, finaliza la historia de Flora: "¿Quién es usted? -preguntó Elisa Lemonnier. -Mi nombre no interesa -dijo el hombre, con voz impregnada de sufrimiento y amargura-. Ella me conocía por un feo apodo, con el que me ridiculizan entonces las gentes de esta ciudad: El Eunuco Divino. Pueden ustedes reírse de mí, cuando les dé la espalada" (499). Este personaje le sirve a Vargas Llosa para ilustrar un arquetipo lleno de amargura y sufrimiento, el cual pareciera ser objeto de ridiculización.

Los conceptos de ancien régime y edad de la movilización de Charles Taylor son útiles para analizar la historia de Tristán. Taylor identifica al ancien régime con el período histórico en el cuál había una jerarquía fija y estable determinada por lo sobrenatural, un microcosmo de lo social girando en torno a la villa o la parroquia, unos pobladores que no sentían oposición entre la ortodoxia cristiana y los rituales paganos, y una correlación entre la participación de la iglesia con la comunidad (438-440). En este estadio, los rituales eran centrales ya que tenían una correspondencia con una realidad superior pre-existente, que determinaba el orden social (438-440).

Pero con la irrupción de las reformas, tanto protestantes como algunas católicas, comenzó a haber una condena a todo tipo de magia, sin importar si era blanca o negra, al igual que se menospreciaba los rituales, carnavales y peregrinaciones, considerándose parte del mundo pagano (440-441). También, estas reformas hicieron énfasis en la disciplina como elemento religioso central, enfocándose por ejemplo en la ética del trabajo y el control de los deseos sexuales. Este cambio alentado desde las élites gestó lo que Taylor Ilama la edad de la movilización (445).

En este estadio, las personas eran empujadas, persuadidas o forzadas a nuevas formas de sociedad e iglesia en la que los individuos tenían que poner en práctica el diseño de un Dios creador, el cuál no se entrometía en los asuntos humanos (Taylor 2007: 446-447). Además, existía un énfasis en un orden moral moderno, en el que el comportamiento humano, controlador de las pasiones hacía una sociedad más justa, era el centro de la religiosidad (446-447). Este cambio estuvo acompañado por un proceso de urbanización e industrialización que fue rompiendo el orden agrícola y parroquial, generando a su vez una descristianización y unos movimientos laicos que se ofrecieron como alternativa (443). 
Flora Tristán se representa como la mujer Mesías (Kuhnheim 1995: 34), que, como élite, intenta masificar un nuevo imaginario social, encarnado en su Unión Obrera. Para Flora, los seguidores de Saint-Simon, Fourier y otros socialistas no son sus opositores, ya que, si bien presentan diferencias metodológicas para lograr la utopía social, ellos le sirven de inspiración, comparten varias ideas y logran tener una relación cordial en casi toda la novela. Pero los curas, monjas y religiosos representan el ancien régimen, son los opresores que hay que eliminar.

\section{Paul Gauguin y la edad de la autenticidad}

El ataque a la religión es de otro estilo en la historia de Gauguin, pero igualmente, se establece en oposición al pintor. En el primer capítulo par, el II, ya se puede leer: "Por lo menos en eso, el empeño de los misioneros y pastores para que los maoríes adoptaran el modelo de la estricta familia cristiana, era bastante inútil" (Vargas Llosa 2003a: 34). También, en el capítulo IV, al hablar sobre los taata vahine, los hombres-mujeres, describe: "andróginos o hermafroditas, aquel tercer sexo intermediario que, a diferencia de los prejuicios europeos, los maoríes, a ocultas de misioneros y pastores, aceptaban todavía entre ellos con la naturalidad de las grandes civilizaciones paganas" (74).

Siguiendo esta misma idea, en el capítulo VI, se critica primero a la Vikinga, ex esposa de Gauguin, por ser muy puritana y religiosa, alejada de las pasiones de la vida (138). Segundo, Gauguin lamenta que algunos de sus mejores amigos artistas, al acercarse a la religión, se alejaran de él y hasta lo consideraran ahora su enemigo (127). Y tercero, un párroco francés le reprende por su conducta alocada junto a la Javanesa (128), algo a lo que por supuesto Gauguin no presta atención.

En el capítulo VIII, empieza a describirse algo que se repite en otros capítulos, es el hecho que las niñas de los colegios religiosos, católicos y protestantes, se acercaban a su casa por curiosidad o en búsqueda de placer:

\footnotetext{
... chiquillas traviesas de la vecindad, luego de las clases de catecismo en las iglesias protestante y católica de Panaauia...venías a verlo pintar o esculpir...y él conseguía arrastrar alguna a su alcoba y gozar de ella del todo o a medias... El trasiego de chiquillas le trajo conflictos, primero con el cura católico, el padre Damián, y luego con el pastor, el reverendo Riquelme [...]. Pero... Si no hacía el amor, la inspiración se le escabullía. Así de simple, señores. (Vargas Llosa 2003a: 171)
}

La disputa de Gauguin con el sacerdote y pastor de Panaauia, por su conducta promiscua e "inmoral" continua en el capítulo x $(210,226)$ y en el capítulo XII, que se explicita en la crítica a los religiosos: "Los misioneros embutieron sobre sus cuerpos cobrizos esas túnicas que parecían hábitos. ¡Qué crimen! [...]. Los misioneros les habían arrebatado la memoria, convertido en amnésico" (270-271). Este enfrentamiento lleva a Paul incluso a enterrar a su propia hija sin servicios religiosos (212). 
En el capítulo XIV y XVI, se puede percibir cómo Gauguin pareciera hacerse pasar por católico solo con el fin de ganar dinero (298, 300, 351, 352): "Apenas firmó el contrato de compraventa con el obispado y fue dueño del terreno, Paul se olvidó de las misas y los rosarios..." (351). Además, en su disfraz de católico, experimentó tensiones irreconciliables con los religiosos. Por ejemplo, cuando intentó regalar una de sus obras a una iglesia: "Tú querías para La visión después del sermón un entorno religioso, y ofreciste regalárselo a la iglesia de Pont-Aven. El párroco lo rechazó, alegando que esos colores...conspiraban contra el recato debido de los lugares de culto. Y también lo rechazó, aún más enojado, el párroco de Nizon..." (313).

En los dos capítulos anteriores también se burla de Van Gogh, por considerarlo un ex pastor puritano y loco (357), a la vez que pinta un cuadro burlesco del obispo Martin, su acérrimo enemigo en el final de su historia, por combatir su comportamiento promiscuo e desbocado en La Casa del Placer (397). En los últimos capítulos, Gauguin continúa despotricando contra los misioneros y curas (412-413), por matar la fuerza primitiva de los nativos (459), y al mismo tiempo, en señal de protesta y rebeldía, prosigue atrayendo a las adolescentes de los colegios religiosos a La Casa del Placer $(500,502)$.

Como en la historia de Tristán, el final de Paul Gauguin es muy relevante para nuestro análisis. Por un lado, ya en su lecho de muerte, Gauguin es acompañado por el pastor Vernier. No obstante, el pastor lo tiene que dejar solo y moribundo por sus obligaciones $(517,519)$. Finalmente, una vez muerto, y a pesar de las discusiones con Vernier, el obispo Martin logra su cometido, el cual es enterrarlo rápidamente en un cementerio católico, quitarle y destruirle sus pinturas "pornográficas" y escribir el único epitafio que se considera que tuvo Gauguin, y se trataba de una carta del religioso a sus superiores: "Lo único digno de anotarse últimamente en esta isla ha sido la muerte súbita de un individuo llamado Paul Gauguin, un artista reputado pero enemigo de Dios y de todo lo que es decente en esta tierra" (521-525). Con estas palabras del obispo finaliza la historia de Gauguin y la novela.

Para analizar la historia de Gauguin, es útil el concepto edad de la autenticidad de Charles Taylor. El filósofo canadiense coloca la edad de la autenticidad a partir de 1960, cuando, según él, un imaginario social particular se convirtió en un fenómeno masivo y cambió las estructuras sociales (2007: 475). No obstante, Taylor aclara que los artistas románticos y de principio del siglo $\mathrm{xx}$, como Paul Gauguin, ya venían defendiendo de manera individual esta perspectiva de sociedad e intentando propagarla hacia el imaginario social por medio de su arte. La edad de la autenticidad defiende un individualismo ya no moral ni instrumental, sino expresivo. El individuo debe buscar su propio camino para expresar su identidad y en donde el hedonismo y el gusto juegan un papel primordial (474475). La demanda por el placer, principalmente sexual, es una puerta de libertad frente a una moral puritana y ascética defendida por la religión y el orden moral moderno. Además, la posibilidad de elegir es fundamental y cualquier tipo de coacción externa es vista no solo como mala, sino absurda y obscena (474). Finalmente, lo religioso se limita a lo que despierta sentimientos y pasiones lejos 
de cualquier construcción teológica coherente (488). En este sentido, al igual que Tristán, Gauguin también representa un agente de secularización, pero ya no frente a los ritos, las peregrinaciones y lo sobrenatural, sino en contra de los religiosos quienes defienden, como Flora, un orden moral moderno.

\section{LO RELIGIOSO Y LO SECULAR, CATEGORÍAS INTERCAMBIABLES}

Con su acostumbrada pluma magistral y sutil, el escritor peruano coloca sus dos personajes principales de la novela enfrentados constantemente a personas religiosas, sin que sea fácil para el lector reconocer este patrón a través de todos los capítulos. Pero lo que es más interesante es que, la mayoría de las veces, Tristán y Gauguin discuten con los religiosos por razones completamente opuestas. Por ejemplo, mientras Flora está en contra de los ritos y peregrinaciones católicas en Perú y Francia, las cuales califica de ridículas y opresoras, Paul las desea, las busca y las considera liberadoras, criticando a cualquier tendencia por combatirlas, ya sea de los misioneros o de la cultura europea. Esto muestra cómo la oposición secular/religioso es diferente en ambas historias, e incluso llegan a intercambiarse. Por ejemplo, en el caso de la historia de Flora Tristán, los sacerdotes, monjas y obispos franceses parecen fomentar la vida religiosa plagada de rituales que apuntan a una realidad sobrenatural. Pero en el caso de la historia de Gauguin, los misioneros parecieran promover una eliminación de los rituales y símbolos, en conexión con lo sobrenatural, representándose de alguna forma como agentes de una cierta secularización.

En la historia de Flora se puede leer:

Venían después, envueltos en incienso y sahumerios, los penitentes, arrastrando cadenas, cargando cruces, flagelándose, seguidos por una masa anónima de indios que rezaban en quechua y lloraban a gritos. Los cargadores del anda se entonaban con tragos de aguardiente...

-Este pueblo supersticioso produce los peores soldados -le decía Althaus.... (Vargas Llosa 2003: 248)

Y, en cambio, en la historia de Paul Gauguin, la crítica toma una posición contraria: "pueblo primitivo en comunión con la naturaleza y con sus dioses... Lo había buscado en la Bretaña tradicionalista y católica, orgullosa de su fe y costumbres, pero ya la habían mancillado los turistas pintores y el modernismo occidental. Tampoco lo encontró en Panamá, ni en la Martinica, ni aquí, en Tahití..." (224225).

En este sentido, en la historia de Flora Tristán, los religiosos son los enemigos porque promulgan ritos, peregrinaciones y aspiraciones de trascendencia, que solo distraen al pueblo que debería buscar la igualdad en el presente. En cambio, en la historia de Paul Gauguin, los religiosos son los adversarios ya que intenta eliminar los ritos y costumbres de los pueblos que apuntan a lo trascendente, e imponen una igualdad homogeneizadora que limita las potencialidades individuales. 
Lo mismo sucede con los placeres terrenales, específicamente el sexo. En Gauguin, es la puerta a la liberación que los religiosos quieren tapar, mientras que en el caso de Flora, es una fuente de esclavitud. A lo largo de la historia de Tristán, se siente una actitud represiva con respecto al sexo por parte del personaje principal: "En su proyecto de Unión Obrera no había recetas sexuales; salvo la igualdad absoluta entre hombres y mujeres y el derecho al divorcio, el tema del sexo se evitaba" (109). También se puede leer en la novela:

Desde los primeros tiempos de su matrimonio con André Chazal, el sexo la repelía. Antes incluso de adquirir una cultura política, una sensibilidad social, intuyó que el sexo era uno de los instrumentos primordiales de la explotación y dominación de la mujer. Por eso [...] siempre desconfiaba de las teorías que exaltaban la vida sexual, los placeres del cuerpo, como unos de los objetos de la futura sociedad. (Vargas Llosa 2003a: 108)

La oposición de lo sexual, también se puede extender a otras manifestaciones de placeres corporales y libertades en los deseos. Por ejemplo, el alcohol y los borrachos le causaban un gran rechazo a Flora Tristán:

... la visita a esas tabernas te removió la memoria [...] de la Place Maubert y alrededores, entre los que pasó tu niñez y adolescencia. Y los cuatro años de matrimonio. ¡Qué miedo los borrachos! [...] A André Chazal le gustaba beber, jugar y perder el tiempo en las tabernas. Cuando estaba con tragos, y a veces sin estarlo, solía propasarse con las obreras. (Vargas Llosa 2003: 51-52)

Pero en Gauguin estos placeres tienen un sentido opuesto y es la causa de sus mayores discordias con los religiosos. Por ejemplo, en el capítulo IV, se comenta: "Solo bastante después, cuando Paul, sin descuidar todavía la agencia de Paul Bertin, dedicaba sus noches a pintar de todo y con todo [...] sus noches comenzaron a encabritarse de deseos. Entonces, implorabas o exigías a Mette en la cama libertades que la escandalizaban" (86).

Y en el mismo capítulo, siguiendo esta conexión entre libertad y sexualidad, se escribe: "Habías dado un nuevo paso hacia la libertad. De la vida del bohemio y el artista, a la del primitivo, el pagano y el salvaje. Un gran progreso. Ahora, el sexo no era una forma refinada de decadencia espiritual, como para tantos artistas europeos, sino fuente de energía y salud, una manera de renovarte [...] para crear mejor, para vivir mejor" (87).

\section{LAS VOCES NARRATIVAS Y LA POROSIDAD DEL MARCO INMANENTE}

La fragilidad de la frontera entre lo religioso y lo secular dibujada por Vargas Llosa también se vislumbra en los cambios de voces narrativas. La novela del escritor peruano utiliza cambios constantes de voces narrativas, de tercera a segunda persona y viceversa. La narración central se lleva a cabo en tercera persona, pero irrumpe más de doscientas veces la segunda persona a lo largo de la novela. Capítulos como el II y el vIII tienen unos diecisiete cambios de persona, 
mientras otros, como el I, V, VII, XXI, XXII, van de cinco a ocho. Es decir, no hay un patrón estable y repetible en todos los capítulos. Pero, como los otros elementos narrativos de la novela, estos cambios de voces también, al entrar en contacto con la temática de la religión, adquieren una connotación particular.

Cuando se analizan los cambios a segunda persona en la narración, todo parece indicar que se trata de la descripción del mundo interno de los personajes principales, tanto pensamientos, recuerdos y sentimientos. De hecho, el mismo Vargas Llosa reafirmó que su intención con la segunda voz en la novela era introducir los pensamientos y sentimientos de los personajes principales (Vargas Llosa 2003b). Por ejemplo, la primera oración de la novela dice: "Abrió los ojos a las cuatro de la madrugada y pensó: 'Hoy comienzas a cambiar el mundo, Florita'" (Vargas Llosa 2003a: 11). Al contrario, la descripción en tercera persona es externa y si llega a mencionar algún tipo de sentimiento o pensamiento, lo hace de manera más superficial: "No se sintió pesimista. Al mal tiempo buena cara, Florita. No le había ido muy bien, pero tampoco tan mal. Rudo oficio el de ponerse al servicio de la humanidad, Andaluza" (24).

No obstante, es interesante cómo en el último cambio de voz narrativa de la novela, en la historia de Gauguin, cobra un sentido diferente: "A partir de allí, ya no vio ni oyó ni supo nada, porque te habías acabado de morir del todo, Koke" (523). Por supuesto, en un plano narrativo inmanente, un muerto no podría reflexionar, a menos que se tratara de un alma resucitada. Esto pone en evidencia una discrepancia, que solo se resolvería aceptando que las segundas voces son algo más que los pensamientos de los personajes, y/o que se trata de una trascendencia de su vida, al estilo judeocristiano, lo cual atentaría con el cuadro inmanente desde donde se desarrolla toda la narración.

Hay que tener en cuenta que la novela de Vargas Llosa comienza con una cita de Paul Valéry que dice: "¿Qué sería, pues, de nosotros, sin la ayuda de lo que no existe?" (9). De hecho, esta cita es la única página de la novela que no pertenece a ninguna de las dos historias en específico, ni a Flora ni Paul. Si esta cita se tratara de las utopías terrenales que buscan ambos personajes, como parece indicar el mismo Vargas Llosa y algunos críticos, sería muy problemática. Por un lado, se pudiera argumentar que la Unión Obrera de Flora Tristán y los derechos femeninos, de alguna forma, sí existen y se volvieron realidad. Y, por otro lado, en el caso de lo utópico en Gauguin, se pudiera objetar también que el pintor francés buscaba un estado primitivo que quedara atrapado en sus pinturas, y para muchos, lo logró, haciéndolo existencia. En otras palabras, el concepto de utopía en la novela es ambiguo y puede ser interpretado de muchas maneras.

No obstante, creo que la cita de Vargas Llosa va dirigida principalmente, consciente o inconscientemente, a la religión. El paraíso es, sin lugar a dudas, un término principalmente religioso. Con ello, Vargas Llosa no se refiere solo a las razones de vida de Tristán y Gauguin, sino, más bien, a la de sus personajes antagónicos. En la novela, Paul y Flora llegan a realizar una parte de sus utopías, pero los religiosos esperan algo que, según parece sugerirse, no existe. Sin embargo, en este punto, la frontera de lo religioso vuelve a mostrar su porosidad a lo largo de la novela y el ejemplo más crucial es en el último cambio de voz 
narrativa de la novela, casi al final de esta, cuando Paul Gauguin parece hablar después de muerto con su identidad intacta, al estilo judeocristiano. Después de toda la crítica de la novela a una búsqueda de un paraíso que supuestamente no existe, el cambio de voz del final de la obra invita a pensar que Gauguin solo lo consiguió al morir. Gauguin habla desde un más allá, que se parece al paraíso judeocristiano o si no, por qué no, al purgatorio o al infierno.

\section{EL LECTOR Y LA RESISTENCIA A LA OPOSICIÓN BINARIA DEL NARRADOR}

Los cambios de voces narrativas en la novela también tienen características comunes, como la infantilización, especialmente con diminutivos y apodos: Florita, Andaluza y Koke. Frente a una tercera persona que pretende ser más lejana y objetiva, la segunda persona se utiliza como acercamiento al personaje y para darle un carácter subjetivo a las historias. Además, la apelación a los recuerdos en la narración en segunda persona, le permite a Vargas Llosa cambiar de tiempo y espacio, sin que el lector detecte ninguna variación brusca. En otras palabras, la segunda persona le sirve a Vargas Llosa como un sistema de túneles temporales y espaciales: "Cuando regresaba al albergue por las callecitas curvas y adoquinadas de Auxerre... un grupo de niñas que jugaban... Se detuvo a observarlas. Jugaban al Paraíso. [...] ¿Te acordabas, Florita?... la impresión de aquel día en Arequipa, el año 1833..." (20).

Pero más importante es que con las preguntas, cuestionamientos y justificaciones que se repiten en las narraciones en segunda persona, Vargas Llosa pareciera intentar poner a los lectores en el lugar de los dos personajes principales y de alguna forma, justificar sus comportamientos. Mientras las narraciones en tercera persona son principalmente descriptivas, las otras, en segunda persona, son explicativas y justificativas. Por ejemplo, se lee en la historia de Flora cosas como: "Alguna vez, incluso, dejaste que los labios de Chabrié rozaran los tuyos. ¿No te arrepentías? No." (198). En la historia de Gauguin, por otro lado, se lee: "en busca del mundo primitivo, no había sido inútil. No, Paul...habías pintado una treintena de cuadros..." (31). Y en otra parte se dice: “¿No te importaba ver más a tus hijos, ni a los amigos, Paul?... Bah, no te importaba lo más mínimo" (162).

No obstante, a pesar de los intentos de justificación de la conducta de Flora y Paul, sus comportamientos con los demás personajes pueden despertar fácilmente cierto rechazo y antipatía en el lector. Los proyectos ideales de ambos, en muchos momentos de la novela, no calman un cierto reclamo por acciones como el abandono de sus hijos o la utilización de las demás personas para beneficio personal. Uno de los ejemplos más significativos es el de Gauguin con su apetito incontrolable por el sexo, que, si bien le permitió producir sus pinturas y encontrar su libertad creadora, se ve menguado por su enfermedad de trasmisión sexual, la cuál va contagiando a todas las indígenas, y a las estudiantes adolescentes de los colegios protestantes y católicos. Flora Tristán hace casi lo mismo, pero a nivel emocional con sus conquistas amorosas, como con Chabrié. 
A pesar de la bondad y amabilidad con ella, Flora utiliza a Chabrié como objeto para lograr sus fines.

En este sentido, la conducta de Gauguin y Tristán, lejos de producir en el lector una simpatía, puede generar una condena y una repugnancia, similar a la opinión de los misioneros. La idealización de la libertad individual como factor absoluto, propia del liberalismo clásico o lo que hoy se identifica con el libertarismo, omite las consecuencias negativas que esta puede causar a los demás y a la comunidad. En esa oposición que presenta Vargas Llosa entre los dos personajes principales y los religiosos, el lector se ve tentado, en repetidas oportunidades, a ponerse del lado de estos últimos. La oposición que propone Vargas Llosa entre religión, asociada a la esclavitud personal y social, y lo secular, que busca la libertad y la realización humana, se revierte en varios puntos de la novela, quebrando la frontera desde donde se coloca el lector.

De hecho, los dos personajes dan la sensación de fracasar en sus proyectos liberadores del control de la religión. Tristán, en el lecho de su muerte, termina confesándose con el Eunuco Divino que a pesar de ser un "falso" sacerdote, sigue siendo la persona más católica en la historia de Flora. El personaje de quien Tristán se burlaba, al final, termina saliéndose con las suyas. Y Gauguin, moribundo en su cama, es acompañado por el pastor protestante, mientras que el único epitafio que recibe es el del obispo Martin.

Como se menciona anteriormente, Vargas Llosa pareciera intentar dibujar una línea fronteriza entre las potencialidades humanas liberadoras y los vicios religiosos esclavizadores. Con astucia literaria, el autor coloca a los religiosos del lado del enemigo, invitando al lector a tomar posición al respecto. No obstante, las conductas, hasta cierto punto, egoístas y dañinas de los personajes principales con los demás, revierten la aparente intención del autor. El lector puede verse fácilmente inclinado a condenar la conducta de Paul y Flora, de la misma manera que lo hacen los personajes religiosos.

\section{CONCLUSIÓN}

El desafío crítico que plantea la novela de Vargas Llosa es la unificación de las dos historias de Flora Tristán y de Paul Gauguin, las cuales parecieran estar solamente ensambladas por razones extratextuales, como su parentesco. Sin embargo, al buscar razones intratextuales, se puede encontrar que ambos personajes están unidos por oposición. Flora, por un lado, se presenta en los capítulos impares, como una mujer que siente un rechazo hacia el sexo y los placeres, busca la aceptación social y la afirmación de la civilización burguesa republicana frente a lo medieval y colonial, además de luchar a favor de la acción social y la justicia y en contra de lo supersticioso. Paul, en contraste, en los capítulos pares, se percibe como un hombre que descubre su vocación junto al creciente deseo de sexo y placeres, busca el rechazo y la negación de la sociedad burguesa y la afirmación de lo supersticioso en las culturas de las colonias, a las cuales ve como superiores, y termina produciendo una defensa de la contemplación artística pasiva como aspiración individual. Pero dichas oposiciones parecen disimularse, 
a su vez, a través de los personajes religiosos, quienes se constituyen como lo antagónico y el enemigo a vencer en ambos casos.

Por eso, a pesar de que ni Mario Vargas Llosa, en sus presentaciones del libro, ni los críticos mencionaran el tema de lo religioso en El paraíso en la otra esquina, en este análisis se expone que existe abundante evidencia literaria para interpretar la obra desde una crítica liberal a la religión, como temática unificadora de la novela. En todos los capítulos, como se indicó anteriormente, los personajes antagónicos de Flora Tristán y Paul Gauguin, son religiosos, ya sean sacerdotes, obispos, monjas, pastores protestantes, o personas muy devotas.

No obstante, las fronteras que dividen a ambos personajes principales de los religiosos se intercambian en las dos historias, y en la mayoría de los casos son contrarias. Lo que representan los religiosos en la historia de Flora, en un contexto de la Era de la Movilización es lo contrario en el caso de Paul Gauguin, quien busca una Era de la Autenticidad. Ambos personajes principales, de alguna manera defienden un tipo de religiosidad. De hecho, por ejemplo, Flora se llama a sí misma la mujer Mesías (Kuhnheim 1995: 34). En concordancia con Talal Asad, se puede evidenciar cómo lo religioso se construye desde la oposición en un contexto particular y no guardan una continuidad transhistórica o esencialista.

Los cambios de voces narrativas, por otro lado, también cobran un sentido diferente en contacto con la temática de la religión. Por un lado, las segundas voces narrativas parecen indicar el pensamiento, los recuerdos y los sentimientos de Flora Tristán y Paul Gauguin. De hecho, el mismo autor confirmó esa intención a la hora de escribir su libro ("Vargas Llosa 2003b). Sin embargo, el último cambio narrativo a segunda persona es muy significativo, ya que rompe con el marco inmanente desde donde se narra toda la novela. Sin percibirse eventos sobrenaturales previos en la novela o confundirlos con fenómenos psicológicos, al final, Paul Gauguin parece hablar después de muerto, manteniendo su identidad intacta al estilo de una resurrección judeocristiana. Mientras que el autor, con la cita de Paul Valéry al principio del libro, el título de la obra, y los continuos cuestionamientos a la idea religiosa de trascendencia, parece sugerir que el paraíso no existe y defiende un marco narrativo inmanente, curiosamente, pone a hablar por última vez a su personaje principal desde el más allá, en una especie de zona sobrenatural.

Finalmente, las segundas voces también intentan justificar la conducta de Flora y Paul, pero sus acciones egoístas que perjudican a los demás personajes, muchos de ellos bondadosos y amables, puede despertar en los lectores una antipatía frente a la escritora y al pintor francés. Es por ello, que, por momentos, y en contra de las aparentes intenciones del autor, el lector se siente tentado a ponerse del lado de los religiosos, personajes antagónicos y adversarios de Tristán y Gauguin, o al menos cuestionar la oposición binaria que creó Vargas Llosa a lo largo de su novela. Un ejemplo claro es cuando los misioneros le reclaman a Gauguin su conducta promiscua, y el lector se entera que el pintor es portador de una enfermedad de transmisión sexual, la cual lo va carcomiendo físicamente, pero que él, sin remordimientos, va esparciendo entre las indígenas y las adolescentes en las colonias. 
En definitiva, con una lectura post-secular de la obra de Vargas Llosa, se intenta mostrar cómo la complejidad cambiante de las realidades religiosas nos impone movernos más allá de oposiciones binarias modernas, esencialistas y transhistóricas, propias del liberalismo clásico, y nos exige nuevos enfoques que atrapen las nuevas formas en que interactúa lo secular con lo religioso.

\section{OBRAS CITADAS}

Asad, Talal (2003): Formations of the Secular: Christianity, Islam, Modernity. Stanford, Stanford University Press.

- (1993): Genealogies of Religion: Discipline and Reasons of Power in Christianity and Islam. Baltimore, Johns Hopkins University Press.

Casanova, José (2012): Genealogías de la secularización. México, Anthropos.

- (1994): Public Religions in the Modern World. Chicago, University of Chicago Press.

Estrada, Oswaldo (2017): “Utopías libertarias y sueños de igualdad: Mario Vargas Llosa y Flora Tristán", América sin Nombre, n. ${ }^{\circ} 22$, pp. 125-135.

Gnutzmann, Rita (2004): "El paraíso en la otra esquina", Alpha, n. ${ }^{\circ} 20$, p. 304.

Gorski, Philip S.; Kim, David; Torpey, John; VanAntwerpen, Jonathan (eds.) (2012): The PostSecular in Question: Religion in Contemporary Society. Brooklyn (NY), Nueva York University Press.

Guiñazú, Cristina (2002): "En el Nombre del padre: Las peregrinaciones de una paria de Flora Tristán", Ciberletras: Revista de crítica literaria y de cultura, n. ${ }^{\circ} 5$.

Gutiérrez-Mouat, Ricardo (2008): "Cosmopolitismo y hospitalidad en El paraíso en la otra esquina, de Mario Vargas Llosa", MLN, vol. 123, n. ${ }^{\circ} 2$, p. 396.

Habermas, Jürgen (2010): An Awareness of what is Missing: Faith and Reason in a PostSecular Age. Malden, Mass, Polity Press.

Hamner, Everett (2009): "Determined Agency: A Postsecular Proposal for Religion and literature, and Science", Religion \& Literature, vol. 41, n. ${ }^{\circ} 3$, pp. 91-98.

Huggan, Graham (2010): "Is the 'Post' in 'Postsecular' the 'Post' in 'Postcolonial'?", Modern Fiction Studies, vol. 56, n. ${ }^{\circ}$ 4, pp. 751-68.

Kuhnheim, Jill S. (1995): "Pariah/Messiah, the Conflictive Social Identity of Flora Tristan". En Doris Meyer (ed.): Reinterpreting Spanish-American Essays-Woman Writers of the 19th and 20th Centuries. Austin, University of Texas Press.

Mączyńska, Magdalena (2009): "Toward a Postsecular Literary Criticism: Examining Ritual Gestures in Zadie Smith's 'Autograph Man'”, Religion \& Literature, vol. 41, n. ${ }^{\circ}$ 3, pp. 73-82.

Marín, Paco (2003): "El paraíso en la otra esquina". 7 Vol. Barcelona, Centro de Estudios y Cooperación para América Latina.

McLennan, Gregor (2010): "The Postsecular Turn", Theory, Culture \& Society, vol. 27, n. ${ }^{\circ} 4$ : 3-20.

Oviedo, José Miguel (2007): Dossier Vargas Llosa. Lima, Taurus.

Taylor, Charles (2007): A Secular Age. Cambridge, Mass, Belknap Press of Harvard University Press. 
Vargas Llosa, Mario (2003a): El paraíso en la otra esquina. México DF, Santillana.

- (2003b): "La belleza de pensar-Mario Vargas Llosa 3-7". Web, 20 de abril.

- (2003c): "Mario Vargas Llosa- 2- Bazar Tv". Online video clip. Youtube. Web. 21 de abril.

- (2018): La llamada de la tribu. Madrid, Alfaguara.

Weitzdörfer, Ewald (2004): "El paraíso en la otra esquina", Alpha (Osorno), n. ${ }^{\circ} 20$, pp. $306-$ 307. 